\title{
Satellite monitoring of the state and dynamics of disturbed natural and technogenic landscapes in Siberia
}

\author{
Nikita D. Yakimov ${ }^{1,2}$, Evgenii I. Ponomarev ${ }^{1,3}$ and Tatiana V. Ponomareva ${ }^{1,3}$ \\ ${ }^{1}$ Siberian Federal University, Krasnoyarsk, Russia \\ ${ }^{2}$ Federal Research Center "Krasnoyarsk Science Center SB RAS”, Krasnoyarsk, Russia \\ ${ }^{3}$ V.N. Sukachev Institute of Forest SB RAS, Federal Research Center "Krasnoyarsk Science Center SB RAS”, Krasnoyarsk, \\ Russia
}

\begin{abstract}
A method for monitoring recovery process in post-fire and post-technogenic landscapes was proposed based on satellite data in wide spectral range including the infrared bands data. The spectral albedo in short-wavelength bands (MODIS band \#1 and \#2) was underestimated by $20-48 \%$ relative to the background in the first year after the wildfire and remained underestimated by $3-12 \%$ after 20 years of vegetation restoration. For the variant of post-technogenic plot with reclamation, the albedo value was corresponded to the dynamics in post-fire plots, while for post-technogenic dumps without reclamation the level of the albedo underestimation remained $45-60 \%$ throughout the observation period ( $>60$ years). A decrease in the spectral albedo of the surface in post-fire areas, due to destruction of on-ground vegetation, provokes excessive heating of surface and upper soil layer. Surface thermal anomalies were evaluated under conditions of changes in the heat-insulating properties of vegetation and ground cover. Temperature anomalies in post-fire plots (overestimation up to $30 \%$ ) are typical for permafrost conditions of Siberia. Similar process was recorded for both natural (post-fire) and post-technogenic landscapes. Within 20 years of the fire, thermal insulation properties of the vegetation cover restore. Thus, the relative temperature anomaly has reached the background value of $3 \pm 1 \%$. In post-technogenic plots conditions are more "contrast" compared to the background, and restoration of the thermal regime takes significantly longer period (> 60 years). Forming "neo-technogenic ecosystems" are characterized with specific thermal regimes of soils compared to the background ones both for reclaimed and for non-reclaimed post-technogenic plots. In averaged, surface temperature has overestimated at least by $10-15 \%$ in post-technogenic plots.
\end{abstract}

\section{Keywords}

post-fire and post-technogenic landscapes, satellite data, monitoring, disturbances, albedo, surface temperature, thermal anomalies.

\section{Introduction}

Satellite monitoring allows estimating the annual increase of vegetation disturbances in Siberia, which are associated with a number of destructive natural (insect pests, wildfires, other natural processes) or human-made factors (logging, activities of the mining complex etc.).

SDM-2021: All-Russian conference, August 24-27, 2021, Novosibirsk, Russia $\bigoplus$ nyakimov96@mail.ru (N.D. Yakimov); evg@ksc.krasn.ru (E. I. Ponomarev)

(c) (1) ๑ 2021 Copyright for this paper by its authors. Use permitted under Creative Commons License Attribution 4.0 International (CC BY 4.0).

CEUR Workshop Proceedings (CEUR-WS.org) 
Disturbance of heat-insulating properties of the soil and the vegetation cover is the reason for the change in thermal regime within local areas. With the accumulation of such changes, they should be considered as a significant impact, which regulates the state and dynamics of ecosystems, soil and permafrost layers peculiarities [1, 2, 3, 4]. Up to $20 \%$ of permafrost larch forests in Siberia $[5,6]$ are subject to post-fire changes in vegetation and in surface and soils temperature regime. Anomalous heating of the surface and the soil layer is also observed in post-technogenic plots (open pit mining, quarries, overburden dumps, loggings etc.) under the conditions of strong mechanical impact on vegetation cover and soil. Monitoring the thermal regime of landscapes, as well as the development of remote methods for recovery processes controlling is an urgent problem. The issue can be effectively solved using satellite data in a wide range of spectrum, including data in the infrared (IR) range.

Destructive impact on on-ground cover affects surface albedo, emissivity, moisture and water regimes of the upper soil horizons. As a result, there is a significant change in the temperature regime of soils compared to the background areas. Such thermal anomalies of surface and soil can remain significant for a long time in post-fire plots $[3,4,5]$ as well as in post-technogenic areas, when the ground cover and soils are disturbed mechanically [7, 8].

The main aim of this work was to compare long-term peculiarities of thermal anomalies in post-fire and post-technogenic plots in Siberia based on Landsat survey data in the infrared (IR) range. In addition, using time series of Terra/MODIS satellite data, we performed indirect assessments of disturbed ecosystems recovery in terms of disappearing the spectral features anomaly (spectral albedo in the short-wavelength bands and vegetation index) compared to characteristics of the background areas.

\section{Materials and methods}

We used satellite images of average spatial resolution (15-30 m) from Landsat-5/7/8 for 19752020, which are freely available in The United States Geological Survey (USGS) database (https: //earthexplorer.usgs.gov, accessed on June 20,2021). The surface temperature was evaluated from the calibrated B6 channel ( $\lambda=10.4-12.5 \mu \mathrm{m}$, Landsat-5/TM - Thematic Mapper), B6/1 channel (Landsat-7/ETM - Enhanced Thematic Mapper), and B10 channel $(\lambda=10.6-11.9 \mu \mathrm{m}$, Landsat-8/OLI - Operational Land Imager). We implemented radiometric correction method to the initial data using calibration constants from the metadata files [9].

Next, we used low spatial resolution survey data $(250-1000 \mathrm{~m})$ from Terra/MODIS (Moderate Resolution Imaging Spectroradiometer) for 2002-2020. Standard products L2G and L3 used (free USGS database, https://lpdaac.usgs.gov/dataset_discovery/modis, accessed on May 21, 2021). To analyze NDVI (Normalized Difference Vegetation Index) and albedo, we operated with reflectances measured in MODIS bands \#1 $(\lambda 1=0.620-0.670 \mu \mathrm{m})$ and $\# 2(\lambda 2=0.841-$ $0.876 \mu \mathrm{m}$ ) (standard product MOD09GQ), and to analyze surface temperature anomalies we used the MOD11A1 standard product. We used 10-day averaged data across the entire set of initial data, with a special focus on the disturbed ecosystem's recovery succession stages. A monthly data average procedure, as well as a procedure of spatial averaging within each post-fire or post-technogenic plots, was applied.

We have selected the time series of satellite data for two variants of plots with disturbed 
vegetation and soil cover: 1) post-fire plots (PF) for 1996-2018, and 2) post-technogenic plots for 1975-2019 (Figures 1-3).

We analyzed data for 30 post-fire plots recorded in Siberia in 1997, 2006, 2016, and the dynamics of spectral anomalies for two technogenic plots: Borodinsky Coal Mine (BCM) for 1955-2018 and Olimpiada Mining Plant (OMP) for 1989, 2000, 2019. Time series of satellite data allowed us to perform indirect assessments of disturbed plots recovering. We evaluated long-term changes of spectral features anomaly (albedo and surface temperature) comparing to characteristics of the background areas, as well as the period of stabilization of the properties of disturbed ecosystems.

We evaluated albedo and surface temperature anomalies during 1, 5, 10, 20, 40, 60 years after impact a destructive factor. The value of anomalies was compared with the data in background areas.

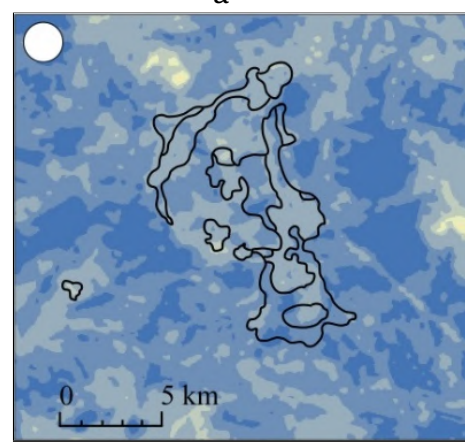

$0.0-16.0$
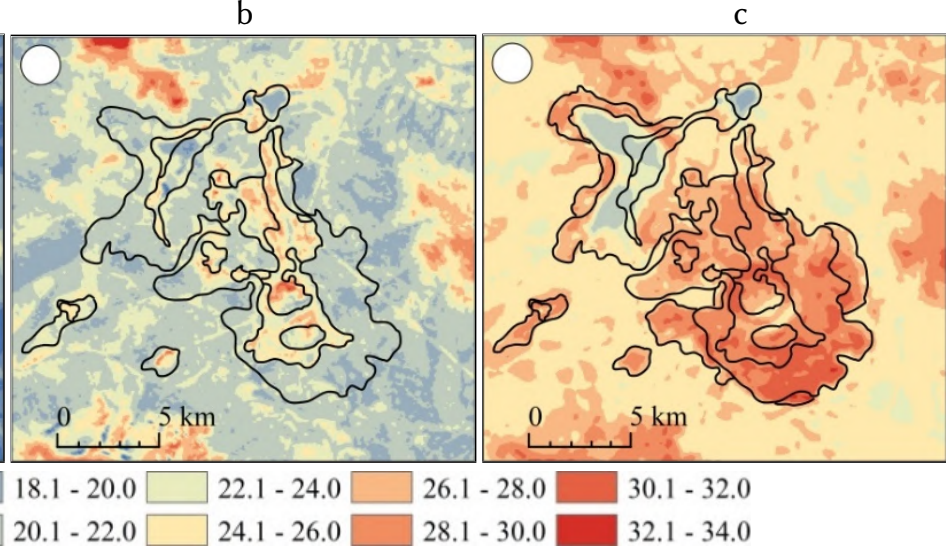

$18.1-20.0$

$22.1-24.0$

$26.1-28.0$

$30.1-32.0$

$20.1-22.0$

$24.1-26.0$

$28.1-30.0$

$32.1-34.0$

Figure 1: Satellite data on surface temperature in OMP plot with the identification of different-aged zones of a technogenic ecosystem formation (since 1989) on dumps in 1989 (a), 2000 (b), and 2019 (c).

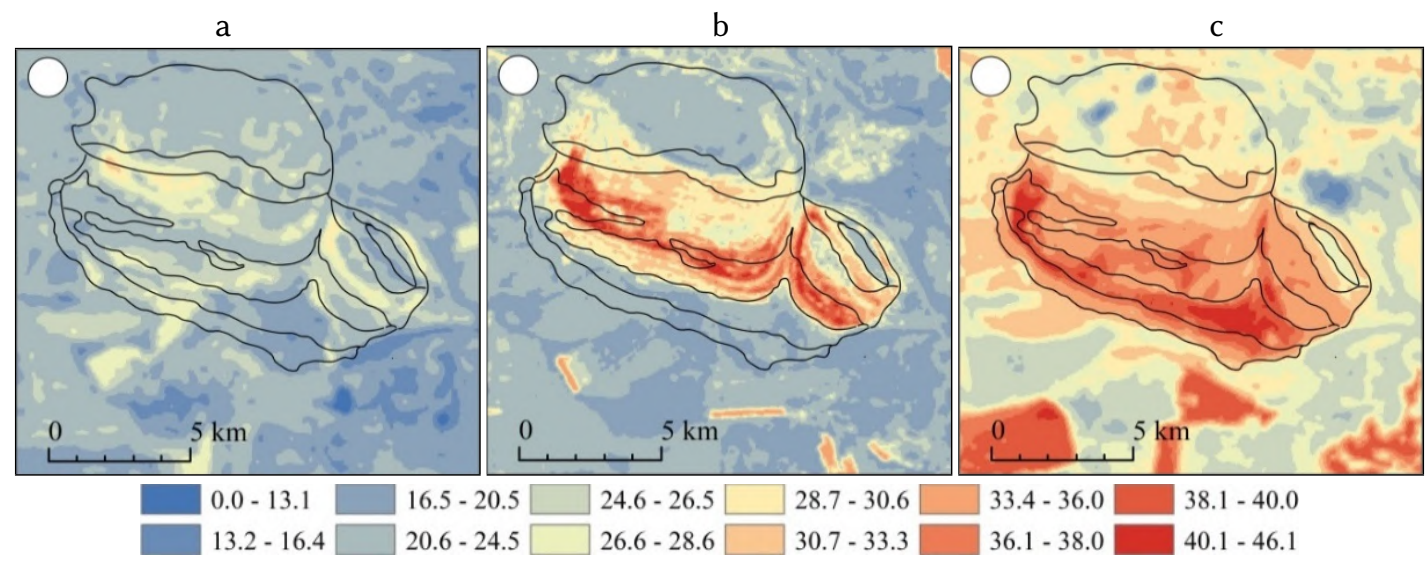

Figure 2: Satellite data on surface temperature in BCM plot with the identification of different-aged zones of a technogenic ecosystem formation (since 1955) on dumps with reclamation in 1990 (a), 2000 (b), 2018 (c). 


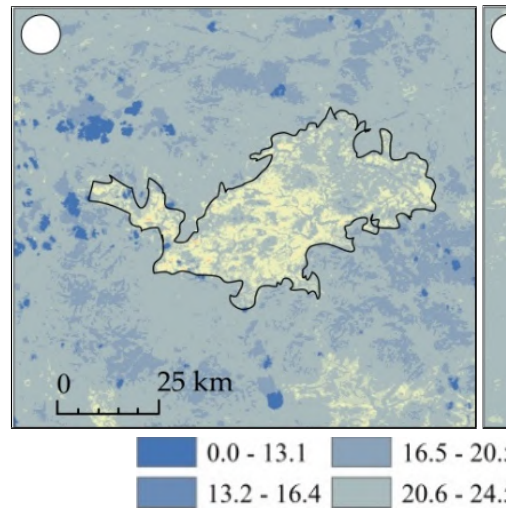

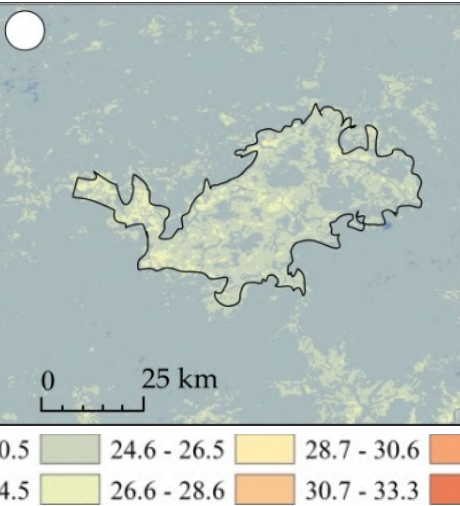

C

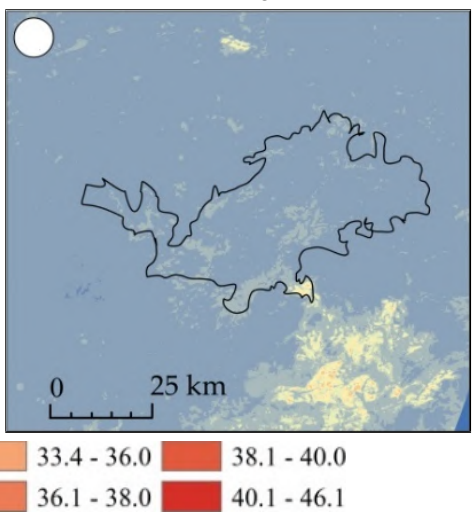

Figure 3: Time series of satellite data on surface temperature in post-fire plot burned in 1997 after the 1st year of recovery (a), 10-years recovery in 2006 (b), and 20-years recovery in 2016 (c).

Relative anomalies of the surface temperature in disturbed plots compared to the background $\left(\Delta T / T_{\mathrm{bg}},{ }^{\circ} \mathrm{C} /{ }^{\circ} \mathrm{C}\right)$ were calculated, using equation:

$$
\frac{\Delta T}{T_{\mathrm{bg}}}=100 \cdot \frac{T_{\mathrm{tg}}-T_{\mathrm{bg}}}{T_{\mathrm{bg}}},
$$

where $T_{\mathrm{tg}}$ is surface temperature of target (disturbed plot), ${ }^{\circ} \mathrm{C}$, and $T_{\mathrm{bg}}$ is surface temperature of background (non-disturbed) plot, ${ }^{\circ} \mathrm{C}$. Each measurement is averaged over 10 measurements for each period of recovery.

To determine the relative vegetation anomalies of disturbed plots compared to the background $\left(\Delta \mathrm{NDVI} / \mathrm{NDVI}_{\mathrm{bg}}\right)$, we used equation:

$$
\frac{\Delta \mathrm{NDVI}}{\mathrm{NDVI}_{\mathrm{bg}}}=100 \cdot \frac{\mathrm{NDVI}_{\mathrm{tg}}-\mathrm{NDVI}_{\mathrm{bg}}}{\mathrm{NDVI}_{\mathrm{bg}}},
$$

where $\mathrm{NDVI}_{\mathrm{tg}}$ is NDVI indicator of target (disturbed plot), and $\mathrm{NDVI}_{\mathrm{bg}}$ is NDVI indicator of background (non-disturbed) plot. Each measurement is averaged over 15 measurements for each period of recovery.

\section{Result and discussions}

The long-term dynamics of albedo $(\alpha)$ and surface temperature anomalies in disturbed plots of natural (PF) and technogenic (BCM, OMP) landscapes in comparison with the background data are summarized in Table 1.

Temperature anomalies in post-fire areas are typical for permafrost conditions of Siberia $[6,10]$. The spectral albedo of disturbed areas in all variants (PF, BCM, OMP) significantly differs from the background values (Table 1). At the initial stages (during the first years after the destructive factor impact), this factor significantly affects the absorption of solar radiation. A decrease in the spectral and broadband albedo $(\alpha, \%)$ in post-fire areas, due to partial or complete combustion of on-ground vegetation cover, provokes excessive heating of the surface and upper soil layer. 
Table 1

Changes in the spectral characteristics of disturbed areas in \% to background values in plots of PF, BUR (reclamation), OMP (without reclamation). Long-term mean value for July $\pm \mathrm{SD}, p<0.05$.

\begin{tabular}{|c|c|c|c|c|c|c|}
\hline \multirow{2}{*}{ 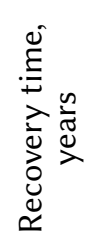 } & \multicolumn{2}{|c|}{$\begin{array}{c}\text { Albedo underestimation, } \% \\
\lambda=0.620-0.670 \mu \mathrm{m}\end{array}$} & \multicolumn{2}{|c|}{$\begin{array}{c}\text { Albedo underestimation, } \% \\
\lambda=0.841-0.876 \mu \mathrm{m}\end{array}$} & \multirow{2}{*}{\multicolumn{2}{|c|}{ 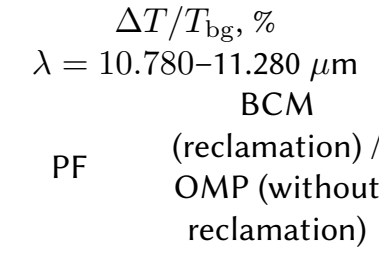 }} \\
\hline & $\begin{array}{c}\mathrm{PF} / \mathrm{BCM} \\
\text { (reclamation) }\end{array}$ & $\begin{array}{c}\text { OMP } \\
\text { (without } \\
\text { reclamation) }\end{array}$ & $\begin{array}{c}\mathrm{PF} / \mathrm{BCM} \\
\text { (reclamation) }\end{array}$ & $\begin{array}{c}\text { OMP } \\
\text { (without } \\
\text { reclamation) }\end{array}$ & & \\
\hline 1 & $17.5 \pm 4.8$ & $53.1 \pm 11.3$ & $48.5 \pm 1.5$ & $46.8 \pm 5.2$ & $28.5 \pm 3.4$ & $77.9 \pm 10.4$ \\
\hline 5 & $16.9 \pm 5.6$ & - & $27.5 \pm 3.6$ & - & $15.0 \pm 2.5$ & - \\
\hline $10-12$ & $15.4 \pm 5.5$ & $50.6 \pm 8.1$ & $25.0 \pm 3.7$ & $51.4 \pm 5.6$ & $12.5 \pm 1.1$ & $55.0 \pm 8.3$ \\
\hline $20-22$ & $3.1 \pm 0.2$ & $62.9 \pm 13.9$ & $12.5 \pm 1.1$ & $50.2 \pm 5.5$ & $3.6 \pm 0.6$ & $43.0 \pm 6.2$ \\
\hline 30 & - & - & - & - & - & $32.4 \pm 4.5$ \\
\hline$>40$ & - & - & - & - & - & $18.7 \pm 0.3$ \\
\hline$>60$ & - & - & - & - & - & $13.5 \pm 0.3$ \\
\hline
\end{tabular}

According to remote measurements (Table 1), the spectral albedo in the short-wavelength bands (MODIS band \#1 and \#2) is underestimated by 20-48\% relative to the background in the first year after the wildfire, by $15-25 \%$ after 10 years of recovery, and remained still underestimated by $3 \%$ (sporadically up to $12 \%$ ) after 20 years of vegetation restoration.

For the variant of post-technogenic plot BCM (with reclamation), the albedo values correspond to the dynamics in PF, while for OMP (dumps without reclamation) the level of the albedo underestimation remained $45-60 \%$ throughout the observation period (Table 1).

Under conditions of positive air temperatures in summer, as well as in spring and earlyautumn, the effect of significant surface temperature anomalies $\left(\Delta T / T_{\mathrm{bg}}, \%\right)$ was recorded in all variants of the disturbed plots (PF, BCM, OMP) in comparison with background surface temperature.

After fire impact, the value of $\Delta T / T_{\mathrm{bg}}$ reaches of $33 \pm 6 \%$ with maxima of $\sim 46 \%$ in PF plots. During 10-12 years the value of the temperature anomaly decreases to $\sim 12.5 \pm 1 \%$ (with sporadic maxima $\sim 20 \%$ ). During at least 20 years the amplitude of anomaly decreases to background values of $3 \pm 1 \%$ (Table 1, Figure 4, a).

We divide the time series of anomalies dynamics into two characteristic periods: the time of an exponential anomalies decrease $\left(T_{\mathrm{rec}}\right)$ as a result of the vegetation cover restoration and the time of stabilization $\left(T_{\mathrm{stab}}\right)$ of the spectral characteristics of disturbed areas. During the period under consideration, stabilization of temperature parameters is observed in PF plot, which is determined by recovering of thermal insulation properties of the surface to the pre-fire state under conditions of a successful vegetation restoration $[4,10,11,12]$.

Post-technogenic plots were characterized by a higher level of initial relative surface temperature anomalies up to $100 \%$ of the background. Further, an exponential decrease was observed, similar to PF plot $\left(R^{2}=0.95\right)$ (Figure 4 , a, b). However, the stabilization time lag $\left(T_{\text {stab }}\right)$ was of 40-60 years, while $\Delta T / T_{\mathrm{bg}}$ remained of $18-20 \%$ under the conditions of the vegetation layer recovery (Figure 4, b). A significantly high level of $\Delta T / T_{\mathrm{bg}}$ in technogenic areas remains twice 


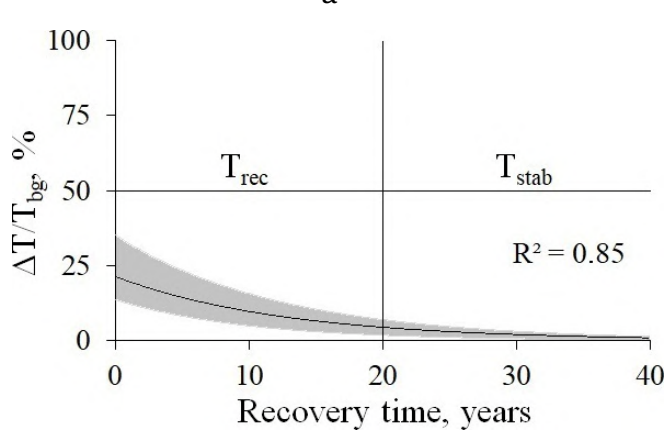

C

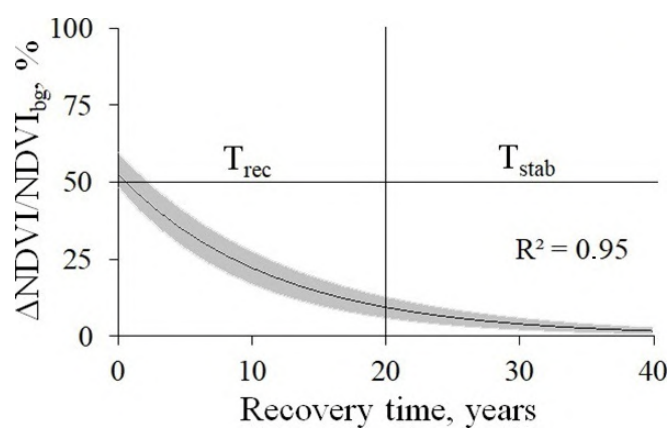

b

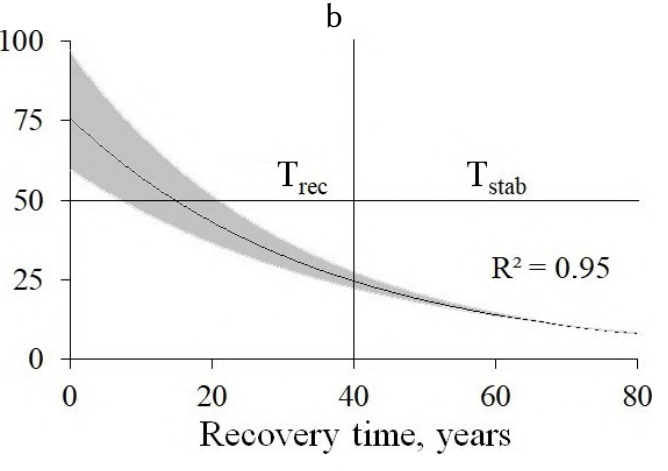

d

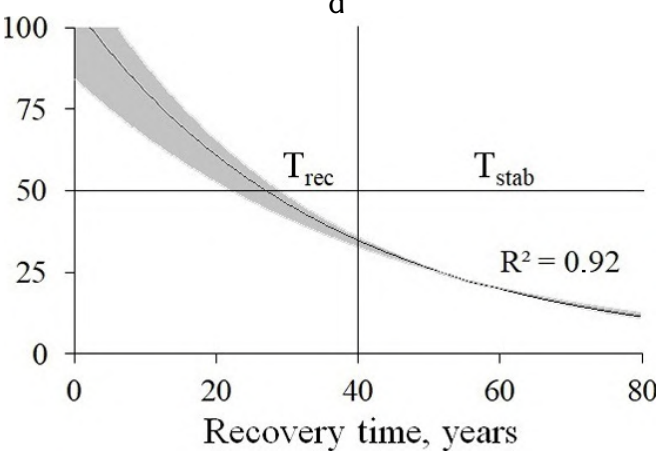

Figure 4: Long-term dynamics of the relative anomaly in post-fire areas $(a, c)$, and in BCM plots (b, d). $T_{\text {rec }}$ is period of intensive recovery, $T_{\text {stab }}$ is period of stabilization of parameters.

as long as in PF plot. In disturbed ecosystems, the morphological and physical properties of the upper soil horizons are not restored to the background level for a long time [3, 4, 11, 12]. Thermal regime remains significantly anomalous over 60 years of recovery succession. Even after the time of stabilization ( $T_{\mathrm{stab}}>60$ years), the level of relative anomaly overestimated at least by $15-20 \%$ in relation to the background values. Probably, we can talk about "neo-technogenic ecosystems" forming, which characterized with special thermal regimes of soils that differ from the background ones both for reclaimed (BCM) and for non-reclaimed (OMP) plots. The main reason for such changes is a significant mechanical effect on the soil and/or complete destruction of its structure, which restoration requires much longer time.

The peculiarity of plots after fire disturbances is that natural recovery processes occur there. The peculiarity of post-technogenic plots is that there are two possible options for dynamics of ecosystem: 1) restoration after reclamation, or 2) long-term condition in the format of nonreclaimed lands (dumps, mineralized surfaces). Each of these options is of interest from the point of view of the formation of surface temperature anomalies and its effect on the properties of soil horizons $[4,10,11,12,13]$.

In addition, using time series of Terra/MODIS satellite data, we performed assessments of disturbed ecosystems recovery in terms of vegetation index (NDVI) compared to characteristics of the background areas.

The ranges of long-term NDVI mean value in disturbed pots for July are summarized in Table 2. 


\section{Table 2}

Changes in the vegetation characteristics of disturbed areas in $\%$ to background values in plots of PF, BUR (reclamation), OMP (without reclamation). The range of long-term mean value for July.

\begin{tabular}{c|ccc}
\hline \multirow{2}{*}{ Recovery time, years } & \multicolumn{4}{|c}{$\Delta \mathrm{NDVI}^{\mathrm{N} N \mathrm{NI}_{\mathrm{bg}}, \%}$} \\
& $\begin{array}{c}\text { PF (natural restoration } \\
\text { of vegetation) }\end{array}$ & $\begin{array}{c}\text { OMP (without } \\
\text { reclamation) }\end{array}$ & $\begin{array}{c}\mathrm{BCM} \\
\text { (reclamation) }\end{array}$ \\
\hline 1 & $50-65$ & 100 & $90-100$ \\
5 & $30-41$ & - & - \\
$10-12$ & $18-26$ & - & $73-100$ \\
20 & $5-10$ & - & $65-77$ \\
30 & - & - & $33-48$ \\
$>40$ & - & - & $25-27$ \\
$>60$ & - & & $18-22$ \\
\hline
\end{tabular}

* No changes in vegetation index dynamics under the conditions of not-reclaimed mining quarry.

The dynamics of relative vegetation index anomalies of disturbed plots compared to the background $\left(\triangle \mathrm{NDVI} / \mathrm{NDVI}_{\mathrm{bg}}\right)$ was evaluated for the PF plots and post-technogenic plots with reclamation (BCM), while in case of non-reclaimed plots (OMP) $[13,14,15]$ dynamics were not fixed due to lack of vegetation restoration (Table 2).

Long-term average NDVI of background was $~ 0.6$. After fire impact (PF plots), the value of $\triangle \mathrm{NDVI} / \mathrm{NDVI}_{\mathrm{bg}}$ reaches of $50-65 \%$ (with sporadic maxima in some plots $\sim 80 \%$ depending the intensity of wildfire). During 10-12 years, the value of the vegetation index anomaly decreases to $15-18 \%$ (with sporadic maxima $\sim 26 \%$ ). After $15-20$ years (the time of stabilization $\left(T_{\mathrm{stab}}\right)$ of the spectral characteristics), the amplitude of anomaly decreases to background values and could be underestimated $<5 \%$ of background values (Table 2). We used exponential function to approximate $\left(R^{2}=0.95\right)$ the dynamics of $\Delta \mathrm{NDVI} / \mathrm{NDVI}_{\mathrm{bg}}$ (Figure $\left.4, \mathrm{c}\right)$. It should be noted [5], that the rate of recovery of vegetative spectral features is two times higher than the rate of recovery of temperature anomalies, which was also approximated by exponential function $\left(R^{2}=0.85\right)$ (Figure 4, a, c).

In post-technogenic BCM plot we identified different-aged zones of a technogenic ecosystem formation since 1955. Thus, we considered the time series to analyze the dynamics of $\Delta \mathrm{NDVI} / \mathrm{NDVI}_{\mathrm{bg}}$ since anomaly of $100 \%$ after technogenic impact (Table 2, Figure 4, d). Actual data show that until 2000, there was no success restoration of vegetation. At the same time, the instrumental indicators obtained after 20 years show that the zones developed in a later period and reclaimed with the planting of coniferous seedlings have a more intensive restoration of the vegetation cover. Thus, $\Delta \mathrm{NDVI} / \mathrm{NDVI}_{\mathrm{bg}}$ anomaly decreased up to $33-48 \%$ during 30 years, which is similar to value of $\mathrm{PF}$ restoration only during 5 years of natural vegetation recovery.

\section{Conclusion}

Under conditions of the same insolation, plots with disturbances in the upper soil horizons and ground cover are accompanied by the formation of long-term surface temperature anomalies. 
Similar processes were recorded for both natural (post-fire) and post-technogenic landscapes. Within 20 years, the thermal insulation properties of the vegetation cover restore in the postfire areas. Thus, the relative temperature anomaly reaches the level of the mathematical error of measurement. In post-technogenic plots, conditions are more "contrast" compared to the background, and the processes of restoration of the thermal regime take a longer period (>60 years). "Neo-technogenic ecosystems" are formed, characterized with special thermal regimes of soils that differ from the background ones both for reclaimed (BCM) and for nonreclaimed (OMP) plots. Thus, monitoring of surface thermal anomalies can be used as an additional diagnostic criterion of post-technogenic ecosystems state in context of territories development after technogenic impacts.

Using time series of satellite data (Landsat and Terra/MODIS), indirect assessments of disturbed ecosystems recovery is possible in terms of disappearing the spectral features anomaly (spectral albedo in the short-wavelength bands and vegetation index) compared to characteristics of the background areas.

Remote sensing data make it possible to effectively monitor the state of disturbed territories on the scale of regions and natural zones. The proposed approach, based on the use of the thermal range, extended the limit of remote monitoring of the state of disturbed ecosystems to 20-40 years with the ability to control and predict the dynamics of recovery processes based on periodic satellite infrared surveys of the territory.

\section{Acknowledgments}

This work was performed using the subject of project of IF SB RAS No. 0287-2021-0010. This research was partly funded by the Russian Foundation for Basic Research and Government of the Krasnoyarsk krai, and Krasnoyarsk krai Foundation for Research and Development Support, No. 20-44-242002 ("Instrumental monitoring of physical properties and numerical modeling of the state of technogenically disturbed soils in Siberia"), and by Siberian Federal University and Government of the Krasnoyarsk krai, and Krasnoyarsk krai Foundation for Research and Development Support, 2020, No. KF-782 49/20 ("Long-term consequences of extreme fires in the permafrost zone of Siberia by the materials of satellite monitoring").

\section{References}

[1] Knorre A.A., Kirdyanov A.V., Prokushkin A.S., Krusic P.J., Büntgen U. Tree ring-based reconstruction of the long-term influence of wildfires on permafrost active layer dynamics in Central Siberia // Science of the Total Environment. 2019. Vol. 652. P. 314-319.

[2] Orgogozo L., Prokushkin A.S., Pokrovsky O.S., Grenier C., Quintard M., Viers J., Audry S. Water and energy transfer modeling in a permafrost dominated, forested catchment of Central Siberia: The key role of rooting depth // Permafrost and Periglac Process. 2019. Vol. 30. P. 75-89.

[3] Kirdyanov A., Saurer M., Siegwolf R., Knorre A., Prokushkin A.S., Churakova O., Fonti M.V., Büntgen U. Long-term ecological consequences of forest fires in the continuous permafrost zone of Siberia // Environmental Research Letters. 2020. Vol. 15. P. 034061. 
[4] Ponomarev E.I., Masyagina O.V., Litvintsev K.Y., Ponomareva T.V., Shvetsov E.G., Finnikov K.A. The effect of post-fire disturbances on a seasonally thawed layer in the permafrost larch forests of Central Siberia // Forests. 2020. Vol. 11(8). 790. DOI:10.3390/f11080790.

[5] Ponomarev E.I., Ponomareva T.V. The effect of postfire temperature anomalies on seasonal soil thawing in the permafrost zone of Central Siberia evaluated using remote data // Contemporary Problems of Ecology. 2018. Vol. 4. P. 477-486. DOI:10.1134/S1995425518040066.

[6] Kharuk V.I., Ponomarev E.I., Ivanova G.I., Dvinskaya M.L., Coogan S.C.P., Flannigan M.D. Wildfires in the Siberian taiga // Ambio. A Journal of the Human Environment. 2021. DOI:10.1007/s13280-020-01490-x.

[7] Krasnoshchekov K.V., Dergunov A.V., Ponomarev E.I. Evaluation of underlying surface temperature maps on logging sites using Landsat data // Sovremennye Problemy Distantsionnogo Zondirovaniya Zemli iz Kosmosa. 2019. Vol. 16. P. 87-97. DOI:10.21046/20707401-2019-16-2-87-97.

[8] Uzarowicz Ł., Charzyński P., Greinert A., Hulisz P., Kabała C., Kusza G., Kwasowski W., Pędziwiatr A. Studies of technogenic soils in Poland: Past, present, and future perspectives // Soil Science Annual. 2020. Vol. 71(4). P. 281-299. DOI:10.37501/soilsa/131615.

[9] Mishra N., Haque Md.O., Leigh L., Aaron D., Helder D., Markham B.L. Radiometric cross calibration of Landsat 8 Operational Land Imager (OLI) and Landsat 7 Enhanced Thematic Mapper Plus (ETM+) // Remote Sensing. 2014. Vol. 6. P. 12619-12638. 775. DOI:10.3390/rs61212619.

[10] Kornienko S.G. Transformation of tundra land cover at the sites of pyrogenic disturbance: Studies based on LANDSAT satellite data // Kriosfera Zemli. 2017. Vol. 21. P. 93-104.

[11] Bezkorovainaya I.N., Borisova I.V., Klimchenko A.V., Shabalina O.M., Zakharchenko L.P., Ilyin A.A., Beskrovny A.K. The influence of pyrogenic factor on biological activity of soils under conditions of permafrost (Central Evenkia) // Bulletin of KSAU. 2017. Vol. 9. P. 181-189.

[12] Dymov A., Abakumov E., Bezkorovaynaya I., Prokushkin A., Kuzyakov Y., Milanovsky E. Impact of forest fire on soil properties (review) // Theoretical Ecology. 2018. Vol. 4. P. 13-23. DOI:10.25750/1995-4301-2018-4-013-023.

[13] Ponomareva T.V. Estimation of the structural organization of soils of technogenic landscapes based on radiometric survey in the thermal range // Proceedings of Conference "Soils in the Biosphere". Novosibirsk, 2018. P. 410-413.

[14] Ponomareva T.V., Ponomarev E.I., Shishikin A.S. Transformation of soil cover in the mountain-taiga zone of middle Siberia in the development of gold deposits // Conference Proceedings "Environmental, Industrial and Energy Security - 2020". Sevastopol, 2020. P. 447-450. ISBN:978-5-6044481-3-7.

[15] Ponomareva T.V., Kovaleva N.M., Shishikin A.S., Ponomarev E.I. Biodiversity assessment in the area of Olimpiada mining and processing plant, Polyus Krasnoyarsk // Gornyi Zhurnal. 2020. Vol. 10. P. 48-53. DOI:10.17580/gzh.2020.10.02. 